\title{
AL-A'RAF
}

Jurnal Pemikiran Islam dan Filsafat

SURAKARTA

http://ejournal.iainsurakarta.ac.id/index.php/al-araf

ISSN: 1693-9867 (p); 2527-5119 (e)

DOI: 10.22515 /ajpif.v14i1.587

\section{PESANTREN DAN PERUBAHAN SOSIAL: OPTIMALISASI MODAL SOSIAL BAGI KEMAJUAN MASYARAKAT}

\section{Dakir \& Umiarso}

IAIN Palangkaraya

Universitas Muhammadiyah Malang

\begin{tabular}{l}
\hline \\
\hline Keywords: \\
Poverty, \\
Pesantren, and \\
Social Capital \\
\end{tabular}

\begin{abstract}
Abstrak
Kemiskinan merupakan problematika sosial-kemanusiaan di Indonesia maupun di dunia. Pesantren dengan modal sosial yang dimilikinya dapat berperan sebagai pendorong perubahan sosial ke arah yang lebih baik. Paper ini merupakan sebuah kajian kritis tentang kiprah pesantren dalam memobilisasi nilai dan norma sosial hingga mampu melakukan perubahan sosial dalam perspektif modal sosial. Hasil kajian menunjukkan bahwa melalui modal sosial yang dimilikinya, seperti jaringan sosial (networking) dan kepercayaan (trust), ternyata pesantren mampu menerobos keterbelakangan masyarakat menjadi tata masyarakat yang lebih baik. Bahkan gerak perubahan sosial yang dilakukan pesantren, yang mengintegrasikan nilai keagamaan dengan berbagai bidang kehidupan di masyarakat yang dilandasi semangat kekeluargaan (brotherhood) dan ditopang asas kepercayaan, dalam tataran empiris ternyata menjadi dasar kuat pada hubungan profesional.
\end{abstract}

\begin{abstract}
Poverty is the social-human problem in Indonesia and in the world. Pesantren with its social capital was able to take a role for that encourages social change towards a better direction. This paper is a critical study on the role of pesantren in the mobilization process of social values and norms so that it was able to make social change in the perspective of social capital. The result of the study shows that through its social capital, such as social networking and trust, pesantren was able to break through the backwardness of society into a better society. In fact, the direction of social change conducted by pesantren which is integrating the religious values with the various dimension of social lives, and based on the spirit then supported by the principle of trust, empirically all of these becomes the powerful basis on the professional relationship.
\end{abstract}




\section{Pendahuluan}

Kemiskinan merupakan persoalan serius yang dihadapi oleh dunia saat ini, ${ }^{1}$ terutama di negara berkembang termasuk Indonesia ${ }^{2}$ yang hingga kini sedang melakukan pengaturan melalui perencanaan, mengubah tata lingkungan, penghidupan, dan jati diri masyarakatnya. ${ }^{3}$ Kemiskinan menjadi persoalan mendasar bagi bangsa Indonesia; di mana World Bank pada tahun 2006 merilis bahwa jumlah penduduk Indonesia yang hidup dengan penghasilan kurang dari $\$ 2 /$ hari, hampir sama dengan jumlah total penduduk yang hidup dengan penghasilan kurang dari $\$ 2 /$ hari dari semua negara di kawasan Asia Timur kecuali Cina. ${ }^{4}$ Berdasarkan data Badan Pusat Statistik (BPS) September 2014, angka kemiskinan di Indonesia mencapai 28.553.930 atau $11,47 \%$ dari total penduduk Indonesia. Dari jumlah tersebut, komposisi kemiskinan mayoritas berada di wilayah pedesaan, yaitu 17.919 .460 atau $62,8 \%$, dan sisanya 10.634 .470 atau $37,2 \%$ berada di wilayah perkotaan. ${ }^{5}$

Besarnya angka kemiskinan tersebut, meskipun menggunakan ukuran pendapatan $\$ 1$-per hari, ${ }^{6}$ namun sangat memprihatinkan dan berimplikasi pada berkembangnya persoalan- lain. Pada konteks ini,

1 Emmy Latifah, "Harmonisasi Kebijakan Pengentasan Kemiskinan di Indonesia yang Berorientasi pada Millenium Development Goals," Jurnal Dinamika Hukum 11, no. 3 (2011): 402.; dan lebih detailnya lihat dalam Tim Penulis, Rethinking Poverty: Report on the World Social Situation 2010 (New York: United Nation, 2009).

2 Adrian Vickers, A History of Modern Indonesia (Cambridge: Cambridge University Press, 2013).

3 Tania Murray Li, The Will to Improve: Perencanaan, Kekuasaan, dan Pembangunan di Indonesia (Jakarta: Marjin Kiri, 2012).

4 Staf Bank Dunia, Era Baru dalam Pengentasan Kemiskinan di Indonesia: Iktisar (Jakarta: The World Bank Office, 2006).

5 Subdirektorat Indikator Statistik, ed., Statistik. Indonesia 2014 (Jakarta: Badan Pusat Statistik, 2014), 177-179.

${ }^{6}$ Dengan standar pendapatan US $\$ 1 /$ hari sesuai dengan pendapatan per kapita US $\$ 370 /$ tahun, World Bank memperkirakan bahwa 18\% dari dunia ketiga adalah "sangat miskin" dan 33\% adalah "miskin". Michel Chossudovsky, The Globalization of Poverty and The New World Order (Canada: Global Research, Center for Research on Globalization, 2003), 28. 
Anthony Elliott \& Charles Lemert meyakini bahwa dengan bukti apapun kemiskinan memiliki konsekuensi yang sangat menghancurkan bagi keluarga dan anak-anak. Depresi, stres pasca-trauma, paru-paru, penyakit jantung, kelaparan yang merajalela serta berbagai penyakit lainnya sebagai bentuk dari implikasi tersebut. ${ }^{7}$ Pada level selanjutnya jika kondisi ini dibiarkan tentu akan berakibat pada aspek-aspek lainnya.

Problem kemiskinan yang masih mendera masyarakat Indonesia tidak lepas dari faktor struktural, yakni sistem perekonomian yang tidak egaliter dan kondisi politik yang tidak humanis atau kebijakan pemerintah yang tidak memihak terhadap rakyat kecil. Artinya, kemiskinan ini terbentuk karena struktur masyarakat (kelompok) tertentu yang menguasai sumber daya, sehingga ada masyarakat lain yang tidak mampu untuk menggunakan sumber daya yang ada. ${ }^{8}$ Di sisi lain, ia tidak lepas dari faktor budaya yang membentuk kepribadian masyarakat, seperti sikap irasional, memiliki mitos yang kuat, berorientasi pada masa lalu, dan hanya bergantung pada alam, sehingga mereka memiliki mental fatalistik (nrimo ing pandum; taken for granted) yang setiap saat membelenggu. Pada titik inilah, kemiskinan dianggap bukan persoalan dalam hidup mereka, akan tetapi sebagai fakta yang bersifat given dan membawa pada apa yang disebut Anthony Giddens sebagai kemiskinan mutlak -yaitu suatu situasi ketika manusia secara teratur tidak dapat memenuhi kebutuhan-kebutuhan hidupnya yang paling mendasar. ${ }^{9}$

Pola kepribadian tersebut pada masyarakat pedesaan menjadi fenomena yang sangat lazim hingga ia cenderung menjadi karakteristik yang mendarah daging. Konsekuensinya, ia sulit untuk keluar dari lingkaran kemiskinan dan keterbelakangan. Saat ini pun fenomena kemiskinan

7 Anthony Elliott \& Charles Lemert, The New Individualism: The Emotional Costs of Globalization (London: Routledge, 2006), 11.

${ }^{8}$ Soetomo, Masalah Sosial dan Upaya Pemecahannya (Yogyakarta: Pustaka Pelajar, 2008), 193.

9 Anthony Giddens, Melampaui Ekstrim Kiri Dan Kanan: Masa Depan Politik Radikal (Yogyakarta: Pustaka Pelajar, 2009), 136. 
masih menjadi bagian problematika sosial-kemanusiaan, bahkan menjadi inti dari kehidupan sosial-kemanusiaan bangsa Indonesia, terutama di daerah pedesaan. Pada konteks ini, pesantren, sebagai lembaga pendidikan Islam yang kebanyakan lokasinya berada di daerah pedesaan, mencoba melakukan perubahan terhadap pola mentalitas santri dan masyarakat di sekitarnya. Sebagai contoh, pesantren modern Darussalam, Gontor yang membekali para santrinya dengan nilai-nilai kewirausahaan; atau pesantren Maslakul Huda, Kajen, Pati yang mengembangkan fiqih sosial dengan landasan epistemologis, ontologies, dan dalam pemecahan persoalan sosial yang dihadapi masyarakat, seperti kemiskinan, kekurangan modal, kerusakan lingkungan, kekumuhan, dan sejenisnya. ${ }^{10}$

Upaya tersebut, secara tidak langsung turut mendorong modifikasi tata nilai dan norma dalam kehidupan masyarakat, termasuk pola relasi sosial antar individu yang ada di masyarakat. Kerangka inilah yang membawa masyarakat pada kedinamisan perubahan sosial dengan ide-ide agar mereka bisa keluar dari kemiskinan dan keterbelakangan. Kathy S. Stolley, membenarkan bahwa kedinamisan masyarakat terjadi ketika antara masyarakat dan budaya secara konstan mengalami perubahan sosial; artinya, struktur masyarakat dan budaya mengubah bentuk ke dalam format yang baru. ${ }^{11}$ Seperti yang terjadi di Amerika dengan arus industrialisasi yang di dalamnya terdapat ide-ide yang dihasilkan oleh gerakan buruh dan kelompok-kelompok sosialis. ${ }^{12}$

Berdasarkan latar tersebut, penulis melakukan kajian kritis tentang kiprah pesantren dalam memobilisasi nilai dan norma sosial, sehingga mampu melakukan perubahan sosial, dalam perspektif modal sosial.

${ }^{10} \mathrm{Abu}$ Choir, "Manajemen Entrepreneurship Berbasis Pesantren dalam Pengembangan Sumber Pembiayaan Pendidikan: Studi Multikasus pada Pondok Pesantren Maslakul Huda Kajen Margoyoso, Pondok Pesantren Al-Isti'anah Plangitan Pati, dan Pondok Pesantren Manbaul Huda Kembang Du” (UIN Maulana Malik Ibrahim, Malang, 2016).

${ }^{11}$ Kathy S. Stolley, The Basics of Sociology (London: Greenwood Press, 2005).

${ }^{12}$ Gergoge Ritzer, Sociological Theory (New York: McGraw-Hill, 2011). 
Peran sosial yang dimainkan pesantren, seperti halnya berperan sebagai broker budaya melalui kiai ${ }^{13}$ — sebagaimana dinyatakan Clifford Geertztetap menekankan pentingnya moralitas keagamaan. Walaupun di satu sisi peran ini pada porosnya bersandar pada nilai normatif, seperti kejujuran, amanah (trust), dan jejaring sosial (networking) yang lazim disebut sebagai modal sosial untuk mendorong perubahan sosial.

\section{Modal Sosial: Hal-Hal yang tidak Terpikirkan"}

Modal sosial telah menjadi fokus perdebatan yang intens sejak awal tahun 1990-an sampai pada awal abad ke-20, ${ }^{14}$ dengan ide dasar bahwa masyarakat dapat menggunakan jejaringnya sebagai sumberdaya yang sangat fundamental. Penggunaan jejaring tidak serta merta mampu untuk membingkai polarisasi pencapaian tujuan personal maupun komunitas tanpa ada struktur sosial yang mengaturnya. James S. Coleman dalam analisis modal sosial di bidang ekonomi menekankan keutamaan normanorma bagi pertumbuhan dan perkembangan ekonomi. ${ }^{15}$ Artinya, ide substansi modal sosial perlu dibingkai sesuai dengan norma-norma yang ada untuk mendapatkan implikasi maksimal pada aspek pembangunan masyarakat, atau sebagai kekuatan yang mampu membangun masyarakat sesuai dengan idealitas-ideologik dan karakteristik lokal.

Tingkat modal sosial di lingkungan sering dihubungkan dengan faktor-faktor, seperti stabilitas, integrasi, kepercayaan, solidaritas, dan toleransi, yang pada gilirannya digunakan untuk menjelaskan hal-hal, seperti pertumbuhan ekonomi diferensial atau tingkat kejahatan antar daerah. Banyak kalangan yang kemudian memahaminya sebagai entitas

${ }^{13}$ Nur Kafid, "From Personal to Social Transformation: A Phenomenological Study on the Life of 'Kyai Kampung,"' Komunitas: International Journal of Indonesian Society and Culture 6, no. 3 (2014): 336-344.

${ }^{14}$ Robert D. Putnam, Bowling Alone: The Collapse and Revival of American Community (New York: Simon \& Schuster, 2000), 19.

${ }^{15}$ George Ritzer \& Barry Smart, ed., Handbook of Social Theory (London: Sage Publications, 2003), 280. 
yang mengacu pada kepentingan kolektif jaringan sosial, yang dibangun atas dasar kepercayaan timbal balik. ${ }^{16}$ Begitu pula ketika Robert D. Putnam mendefinisikannya sebagai karakteristik yang ada di organisasi sosial seperti kepercayaan, norma, dan jejaring yang bisa meningkatkan efisiensinya dengan memfasilitasi aksi-aksi yang terkoordinasikan. ${ }^{17}$ Pada definisi ini terdapat tiga varian penting untuk mencapai kebesaran suatu organisasi seperti pesantren, antara lain: a). Kepercayaan yang perlu untuk dibina dan ditumbuhkembangkan; b). Norma sosial yang berlaku perlu ditaati bersama; dan c). Jejaring sosial yang perlu dikembangkan dan dikuatkan.

Robert D. Putnam juga menambahkan bahwa fitur-fitur kehidupan sosial, semisal jejaring, norma, dan kepercayaan, kesemuanya bisa digunakan oleh peserta untuk bertindak bersama-sama agar lebih efektif untuk mencapai tujuan bersama. ${ }^{18} \mathrm{Hal}$ ini telah dibuktikan bahwa di daerah yang memiliki fungsi pemerintahan daerah yang baik dan ekonomi makmur, aktivitas masyarakat tercipta dengan suasana saling kerjasama, memiliki jejaring sosial yang baik, hubungan politik yang mapan, dan partisipasi yang tinggi. Di mana fenomena ini dibaliknya memancar etos saling percaya antar warganya. ${ }^{19}$ Dengan demikian, modal sosial yang terkonfigurasi dalam entitas kepercayaan (trust) mampu untuk memunculkan tatanan pesantren yang ideal, sehingga untuk melakukan perubahan sosial di masyarakat akan terlaksana dengan pola kolektif-kolegial dan kekeluargaan.

Oleh sebab itulah, Marc Hooghe dan Dietlind Stolle menganggap modal sosial sebagai sumberdaya yang sangat urgen untuk masyarakat dan komunitas. ${ }^{20}$ Wajar apabila Pierre Bourdieu menyatakan, modal sosial

${ }^{16}$ Richard T. Schaefer, Sociology: A Brief Introduction (New York: Mc-Graw-Hill, 2010), 13.

${ }^{17}$ John Field, Social Capital (London: Routledge, 2008), 4.

${ }^{18}$ John Field, Social Capital, 35.

${ }^{19}$ Robert D. Putnam, Making Democracy Work: Civic Traditions in Modern Italy (Princeton: Princeton University Press, 1993), 6-7.

${ }^{20}$ Marc Hooghe \& Dietlind Stolle, ed., Generating Social Capital: Civil Society and Institutions in Comparative Perspective (New York: Palgrave Macmillan, 2003), 2. 
merupakan modal hubungan sosial yang akan memberikan sesuatu yang mampu mendukung saat diperlukan; suatu modal yang sangat berharga dan diharapkan, dan sangat diperlukan jika seseorang ingin menarik klien dalam posisi penting secara sosial. ${ }^{21}$ Melalui modal sosial inilah, pesantren mampu mengembangkan dirinya sendiri dan menarik masyarakat menuju tatanan yang baru. Jelasnya, modal sosial merupakan sumberdaya yang sangat berguna yang tersedia untuk seorang aktor melalui hubungan sosialnya. ${ }^{22}$

Karenanya, perlu dibedakan antara modal sosial dengan modal manusia di dalam pesantren, walaupun antara keduanya saling terkait dalam kegiatan sosial. Mengikuti pandangan James S. Coleman, kelompok yang anggota-anggotanya menunjukkan kredibilitas dan memberikan kepercayaan luas satu sama lain akan mampu mengerjakan lebih banyak, daripada kelompok sebanding yang tidak memiliki kredibilitas dan kepercayaan tersebut. ${ }^{23}$ Sehingga jelas bahwa modal sosial merupakan sumberdaya yang berpusat pada bagaimana beragam potensi dan struktur mampu dibangkitkan untuk memanfaatkan peluang, memahami struktur yang hierarkis, jejaring sosial, pelaku, serta jembatan penghubung makromikro (hierarki-individu) untuk kemudian menjadi investasi untuk mendapatkan tujuan bersama. ${ }^{24}$

Berdasarkan deskripsi tersebut bisa dipilah komponen-komponen di dalam modal sosial, antara lain: trust (saling percaya); norms (normanorma); network (jejaring); reciprocity (hubungan timbal-balik); dan fokus pada pencapaian tujuan bersama. Sebagai contoh, gerakan konservasi lingkungan yang dilakukan oleh Pesantren Pabelan, Pesantren An-Nuqayah,

${ }^{21}$ Simon Susen \& Bryan S. Turner, ed., The Legacy of Pierre Bourdieu: Critical Essays (London: Anthem Press, 2011), 18.

22 John Field, Social Capital, 15.

${ }^{23}$ James S. Coleman, Dasar-Dasar Teori Sosial: Foundations of Social Theory (Bandung: Nusa Media, 2011), 421.

${ }^{24}$ Nan Lin, A Network. Theory of Social Capital, ed. et all Dario Castiglione (Oxford: Oxford University Press, 2008), 51. 
Pesantren Maslakul Huda, Pesantren Cipasung, Pesantren Darunnajah, dan beberapa pesantren lain pada era 1980 -an. ${ }^{25}$ Perlu dilihat bahwa komponen saling percaya sangat penting bagi pesantren untuk mengembangkan dan meningkatkan kesejahteraan sosial masyarakat sekitar. Kondisi ini tidak serta merta muncul dan menjadi bagian kehidupan sosial antara pesantren dan masyarakat tanpa ada saling menghargai dan jujur antara keduanya.

Dengan dasar urgensitas kepercayaan tersebut, Robert D. Putnam dalam komposisi konsep modal sosialnya menempatkan kepercayaanselain norma-norma sosial dan jejaring sosial—sebagai lokus utamanya. Di mana hal ini, dalam pesantren, tidak hanya menyangkut dari "sang kiai" secara personal tetapi juga pada mayoritas civitas pesantren. Begiu pula pada konteks yang lebih luas seperti masyarakat modern, maka secara korelatif kepercayaan individu memiliki lokus yang lebih luas yaitu "kepercayaan umum". Kenneth Newton menyatakan bahwa aktor individu melakukan sesuatu untuk kebaikan umum bukan karena mereka tahu individu yang lain, tetapi karena mereka percaya bahwa tindakan mereka sendiri akan "dihargai" melalui perkembangan positif hubungan komunal. ${ }^{26}$ Begitu juga tindakan kiai di pesantren melakukan tindakan untuk mendorong kebaikan komunitas diri mereka dan masyarakat sekitarnya.

Di satu sisi, ada pula komponen lain yang memiliki posisi sangat penting dalam interaksi sosial untuk melakukan perubahan sosial, yaitu network (jejaring sosial). Ia adalah model relasi di antara pesantren dengan masyarakat yang dihubungkan oleh perasaan simpati dan kewajiban, serta oleh nilai dan norma pertukaran. Hakikatnya, pesantren ataupun masyarakat tersusun oleh individu-individu yang berinteraksi setiap hari dengan berbagai kepentingan dan motivasi yang melatarinya. Dari kerangka inilah, modal sosial tidak hanya bermanfaat bagi pengembangan

${ }^{25}$ Husnul Khitam, "Kontekstualisasi Teologi sebagai Basis Gerakan Ekologi," DINIKA: Academic Journal of Islamic Studies 1, no. 2 (2016): 143-164.

${ }^{26}$ Kenneth Newton, Social Capital and European Democracy, ed. Jan Van Dept (London: Routledge, 1999), 8. 
kehidupan sosial pesantren dan masyarakat, tetapi juga memiliki nilai guna di bidang lainnya.

Pembentukan fenomenainteraksi sosial pesantren dengan masyarakat terlebih lagi untuk mendorong masyarakat pada idealitas perubahan sosial sangat perlu ditopang oleh jejaring sosial yang di dalamnya terdapat kepercayaan sebagai pondasinya. Adam Seligman menyatakan, penekanan masyarakat modern pada konsensus berdasarkan jaringan interkoneksi kepercayaan di antara warga, keluarga, organisasi jasa, denominasi agama, asosiasi sipil. Dengan cara yang sama pula, "legitimasi" masyarakat modern didirikan atas "kepercayaan" dari otoritas dan pemerintah sebagai generalisasi. ${ }^{27}$

\section{Pesantren: Peran dan Kompetensinya}

Pesantren merupakan lembaga pendidikan tertua ${ }^{28}$ yang sangat melekat kuat dalam perjalanan kehidupan bangsa Indonesia. Karakteristik yang hingga saat ini masih melekat kuat pada diri pesantren, di mana ia secara kontinu melayani kebutuhan pendidikan masyarakat. Lazim jika beberapa kalangan menyimpulkan, pesantren merupakan simbol yang menghubungkan dunia pedesaan dengan dunia luar, ${ }^{29}$ hingga ia tidak dapat diklaim sebagai suatu institusi sosial yang hanya berbentuk lembaga pendidikan saja, akan tetapi juga merupakan entitas budaya yang mempunyai implikasi terhadap kehidupan sosial yang melingkupinya. ${ }^{30}$

Namun umumnya, pesantren tidak lepas dari "sistem kerajaan". Walaupun ia memiliki corak sintesis dengan latar perkembangan yang

${ }^{27}$ Adam Seligman, The Problem of Trust (Princeton: Princeton University Press, 1997), 14.

${ }^{28}$ Yasmadi, Modernisasi Pesantren: Kritik Nurcholish Madjid Terhadap Pendidikan Islam Tradisional (Jakarta: Ciputat Press, 2002), 59.

${ }^{29}$ In'am Sulaiman, Masa Depan Pesantren: Eksistensi Pesantren di Tengah Gelombang Modernisasi (Malang: Madani, 2010), 3. Lihat pula Martin Van Bruinessen, NU: Tradisi, Relasi-Relasi Kuasa, Pencarian Wacana Baru (Yogyakarta: LKiS, 1999), 238.

${ }^{30}$ Hamdan Farchan \& Syarifuddin, Titik Tengkar Pesantren: Resolusi Konflik Masyarakat Pesantren (Yogyakarta: Pilar Religia, 2005), 1. 
berbeda, ada juga pesantren yang berkembang dari arus tradisional-salafmodern. Di sisi yang lain, ada pula pesantren yang sejak berdirinya telah memproklamirkan diri bergerak di arus modern. Uniknya, kedua pesantren tersebut tetap memasukkan kitab-kitab keagamaan berbahasa Arab yang dihasilkan para ulama dan pemikir muslim lainnya di masa lalu sebagai lokus keilmuannya. Karenanya, ia tetap pada ciri utama sebagai lembaga pendidikan Islam dan sebagai transmiter nilai-nilai normatif Islam ke generasi era sekarang. Pada umumnya, pesantren saat ini telah mengalami pergeseran pada sistem pembelajarannya, ${ }^{31}$ tetapi karakteristik utama sebagai lembaga pendidikan keagamaan Islam masih dipertahankan.

Sebagaimana penelitian Damopolii yang menyimpulkan bahwa pembaruan pendidikan Islam-yaitu pesantren—di Makassar bercorak dinamis pada komponen tujuan pendidikan, bercorak transformatif pada komponen kelembagaan dan keorganisasian, bercorak fleksibel pada komponen kurikulum, bercorak eklektik-inovatif pada komponen metodologi pengajaran, dan bercorak profesional pada komponen tenaga pengajar. Berbagai corak pembaruan pendidikan Islam tersebut dimungkinkan pengidentifikasiannya, sebab usaha-usaha pembaruan pendidikan yang telah dilakukan oleh pihak pengelola pesantren dengan jelas memberikan penekanan pada komponen-komponen tersebut. ${ }^{32}$

Tidak heran jika pesantren ketika memainkan peran sosial lainnya tidak lepas dari idealitas institusional untuk mengembangkan masyarakat sekitar. Walaupun awalnya ia diidentifikasi sebagai "gejala desa", yang kehadirannya hanya untuk mengajari para santri ilmu-ilmu agama. ${ }^{33}$ Melalui seorang kiai, pesantren mampu memainkan peran signifikan dalam proses

${ }^{31}$ Suwarno, "Pergeseran Pemikiran Masyarakat dalam Memilih Lembaga Pendidikan Islam di Kabupataen Ngawi Jawa Timur,” Jurnal Salam 18, no. 1 (2015): 151.

${ }^{32}$ Muljono Damopolii, "Pembaruan Pendidikan Islam di Makassar: Studi Kasus Pesantren Modern Pendidikan Al-Qur'an IMMIM Tamalanrea Makassar" (UIN Syarif Hidayatullah Jakarta, 2006), 334.

${ }^{33}$ Nur Efendi, Manajemen Perubahan di Pondok Pesantren: Konstruksi Teoritik dan Praktik Pengelolaan Perubahan sebagai Upaya Pewarisan Tradisi dan Menatap Tantangan Masa Depan (Yogyakarta: Teras, 2014), 112. 
perubahan sosial. Dalam risetnya, Hiroko Horikoshi menunjukkan bahwa Kiai berperanan kreatif dalam perubahan sosial. Bukan karena sang Kiai mencoba meredam akibat perubahan yang terjadi, melainkan justru karena memelopori perubahan sosial dengan caranya sendiri. ${ }^{34}$

Berdasarkan hal tersebut, pesantren senyatanya telah membuktikan eksistensi dan kipranya menjadi dinamisator dalam fase sejarah nation and character building. ${ }^{35}$ Bahkan ia menjadi pusat perubahan masyarakat melalui kegiatan penyebaran agama dan juga pusat pelawanan terhadap kekuasaan penjajahan. Lazim apabila rentang tahun 1959 sampai 1965 pesantren disebut sebagai "alat revolusi”, maka ketika memasuki era Orde Baru pesentren dianggap sebagai "potensi pembangunan". ${ }^{36}$ Sebab pesantren memang mendorong para santrinya untuk menjadi agen perubahan sosial politik (agent of political and social change). ${ }^{37}$

Semua peran tersebut dapat dilakukan pesantren karena ia mampu membangun nilai profetik di dalam lingkungan kelembagaanya. Dilihat dari model pendidikannya, ia memiliki keeratan dengan orientasi kesadaran diri, perbaikan moralitas dan perilaku, serta keterkaitan dengan nilai-nilai normatif dari sumber agama. Orientasi tersebut membentuk jiwa profetik yang mampu menerjemahkan teks-teks normatif keagamaan dalam kehidupan keseharian civitas pesantren dan melahirkan sikap toleran, moderat, selektif bahkan semangat transformatif di ranah sosial. Hal inilah yang menjadi modal pesantren untuk terus melakukan perubahan sosial, sebagaimana gerakan K.H. Ahmad Rifa'i yang merupakan gerakan keagamaan dengan corak tradisional tapi memiliki implikasi sosial (religiotraditional movement). ${ }^{38}$

${ }^{34}$ Hiroko Horikoshi, Kyai Dan Perubahan Sosial (Jakarta: P3M, 1987).

${ }^{35}$ Ninik Masruroh \& Umiarso, Modernisasi Pendidikan Islam Ala Asyumardi Azra (Yogyakarta: Ar-Ruzz Media, 2011), 144.

${ }^{36}$ Tim Penulis Rumah Kitab, Pendidikan Karakter Berbasis Tradisi Pesantren (Jakarta: Rumah Kitab Kerjasama Renebook, 2014), 9.

${ }^{37}$ Soleh Rosyad, Drs. K.H. Abmad Rifa'i Arief: Kiprah Kyai Entrepreneur (Jakarta: Grasindo, 2011), xxii.

${ }^{38}$ Abdul Djamil, Perlawanan Kiai Desa: Pemikiran dan Gerakan Islam KH. Abmad 


\section{Pesantren dan Modal Sosial}

Pesantren dengan daya pikir reflektif membuka ruang mengembangkan dan meningkatkan taraf kesejahteraan hidup masyarakat dengan memahami persoalan secara rasional. Pola yang dikembangkan pesantren memunculkan terbukanya sistem stratifikasi sosial yang semula sangat tertutup terhadap mobilitas vertikal, dan sekarang kelas sosial teratas banyak diisi oleh masyarakat yang semula berada di kelas bawah. Kondisi yang demikian berimplikasi pada proses transisi dari masyarakat dengan struktur feodal ke suatu masyarakat birokrasi, sehingga tata kemasyarakatan lebih mengedepankan kaidah-kaidah yang telah diakui serta ditaati masyarakat dan dilegalisasikan oleh negara. Wewenang yang ditaati masyarakat adalah wewenang yang muncul dari kerangka legalformal yang berdasarkan sistem hukum; Max Weber pada konteks ini mengistilahkan sebagai wewenang rasional-legal (rational-legal authority). ${ }^{39}$ Pada ranah ini pula, posisi pemerintah sebagai pemegang otoritas yang di dalamnya berfungsi sebagai penopang, mendistribusikan, serta mengatur kerja masyarakat; fungsi ini selaras dengan pandangan Herbert Spencer dalam mencetuskan masyarakat heterogen; ${ }^{40}$ sedangkan dalam pemikiran Eva Etzioni-Halevy dan Amitai Etzioni bisa dikatakan sebagai kerangka transisi dari masyarakat tradisional ke modernitas. ${ }^{41}$

Rifa’i Kalisalak (Yogyakarta: LKiS, 2001), xi.

${ }^{39}$ Max Weber membedakan antara tiga jenis sistem wewenang (otoritas), yakni: tradisional, kharismatik, dan rasional-legal. Detailnya lihat George Ritzer \& Douglas J. Goodman, Teori Sosiologi Modern (Jakarta: Prenada, 2011), 37. Namun yang paling menarik pada hal ini adalah wewenang kharismatik yang tidak diatur oleh kaidah-kaidah, baik yang tradisional maupun rasional. Sifat wewenang ini cenderung irasional. Adakalanya kharisma dapat hilang karena masyarakat sendiri yang berubah dan mempunyai paham yang berbeda. Perubahan-perubahan tersebut sering kali tak dapat diikuti oleh orang yang mempunyai wewenang kharismatik tadi sehingga ia tertinggal oleh kemajuan dan perkembangan masyarakat. Lihat Soerjono Soekanto, Sosiologi: Suatu Pengantar (Jakarta: Rajawali Pers, 2007), 244.

${ }^{40}$ Nanang Martono, Sosiologi Perubahan Sosial: Perspektif Klasik, Modern, Posmodern, dan Poskolonial (Jakarta: Rajawali Pers, 2011), 41.

${ }^{41}$ Eva Etzioni-Halevy \& Amitai Etzioni, Social Change: Sources, Patterns, and Sequences 
Dari alur deskripsi tersebut tampak bahwa terdapat hubungan dialektis antara pesantren (aktor) dengan masyarakat. Masyarakat dengan berbagai nilai dan norma sebagai realitas sosial merupakan suatu entitas yang berdiri sendiri (independen) di luar sana, dan terkadang bisa mempengaruhi individu. Diri individu pada konteks ini juga memiliki potensi-baca: naluri-yang berpengaruh atas tindakannya, tetapi tidak menentukan tindakannya tersebut. Ia terlebih dulu menentukan kerangka realitas sesuai dengan penafsirannya. Peter L. Berger dan Thomas Luckmann menyatakan, konstruksi sosial dibangun melalui pola mendefinisikan tentang kenyataan atau "realitas" dan "pengetahuan". ${ }^{42}$ Jelas tindakan individu tidak bersifat mekanis dan deterministis, sebab ia bisa menentukan tindakannya yang akan diperbuat. Akan tetapi di sisi yang lain, realitas sosial bisa untuk memaksa individu mengikuti kemauan alurnya sebagai bagian dari dirinya. Konteks ini memang menjadi bagian dari teori sosiologi yang pada faktanya mengkaitkan antara hubungan sosial dengan kenyataan individu. ${ }^{43}$

Pesantren dengan gagasan-gagasan yang muncul dari rahim doktrin Islam dan pemikiran ulama salaf berupaya mengiring dan membentuk organisasi sosial yang bertumpu pada jaringan pertalian interpersonal yang kompleks untuk mengikat anggota masyarakat secara kolektif. Di mana Robert D. Putnam membingkai keadaan ini sebagai suatu jaringan sosial yang memiliki nilai kontak sosial berpengaruh terhadap produktivitas individu dan kelompok. ${ }^{44}$ Sehingga mereka bisa menyalurkan gagasannya

(New York: Basic Books, 1974), 177.

42 Peter L. Berger \& Thomas Luckmann, Tafsir Sosial Atas Kenyataan: Risalah Tentang Sosiologi Pengetahuan (Jakarta: LP3ES, 1990), 28 \& 65.

${ }^{43}$ Martin Albrow, Sociology: The Basics (London: Routledge, 2003), 82. Di satu sisi ada suatu teori yang memiliki pandangan bahwa esensi kehidupan sosial terletak pada kemampuan luar biasa manusia untuk mengelola apa yang terjadi di sekitar merekakemampuan mereka untuk melekatkan makna pada realitas-dan kemudian memilih untuk bertindak menurut cara tertentu dalam intepretasi ini. Pandangan ini merupakan esensi dari teori intepretif atau teori tindakan.

${ }^{44}$ John Scott, Sosiologi: The Key Concept (Jakarta: Rajawali Pers, 2011), 240. Lihat juga 
dengan ditopang jaringan sosial yang kuat. Akan tetapi, gagasan yang diusung dalam melakukan konstruksi masyarakat tidak serta merta menjadi bagian "yang dipaksakan" sesuai dengan nilai-nilai normatif yang inovator yakini. Tetapi ia muncul dengan proses dialektika kesejarahan yang ada, sehingga gagasan tersebut didialogkan oleh inovator dengan realitas konkrit yang ada (being), serta meruang dan mewaktu menjadi bagian sejarah kemanusiaan. Inilah yang mungkin sejak Descartes sampai Kant ketika memandang dunia yang dipahami sebagai sebuah konstruksi epistemologis. ${ }^{45}$ Peter L. Berger dan Thomas Luckmann pada konteks ini menyatakan bahwa kesadaran selalu intensional; ia selalu terarah kepada obyek. Kita tidak dapat memahami apa yang dianggap sebagai semacam substratum (dasar) dari kesadaran itu sendiri, melainkan hanya kesadaran tentang sesuatu. ${ }^{46}$

Di mana gagasan-gagasan tersebut akhirnya bermuara pada munculnya masyarakat yang sesuai dengan nilai normatif mereka. Namun kolaborasi rasional dalam perencanaan dan tindakan antara pesantren dan anggota masyarakat tersebut hampir tidak mungkin terwujud tanpa ada proses penyaluran terhadap masyarakat—dalam bahasa Peter L. Berger dan Thomas Luckmann disebut sebagai proses internalisasi. Sedangkan Kenneth D. Benne pada hal ini lebih menekankan pada kemampuan inovator dalam menemukan metodologi yang dapat mengembangkan pemahaman tentang faktor-faktor rasional pada diri anggota dan pemimpin kelompok tersebut. ${ }^{47}$ Pola ini merupakan bentuk dari proses konstruksi realitas yang dalam pandangan Peter L. Berger dan Thomas

dalam Julia Hauberer, Social Capital Theory: Towards a Methodological Foundation (Germany: Spinger Fachmedien, 2011), 53.

${ }^{45}$ Bryan Magee, Memoar Seorang Filosof: Pengembaraan di Belantara Filsafat (Bandung: Mizan, 2005), 190-191.

${ }^{46}$ Luckmann, Tafsir Sosial atas Kenyataan: Risalab tentang Sosiologi Pengetabuan, 29.

${ }^{47}$ Kenneth D. Benne, "The Current State of Planned Changing in Persons, Groups, Communities, and Societies," in The Planning of Change, ed. at all Warren G. Bennis (New York: Holt, Rinehart and Winston, 2008), 79. 
Luckmann dinyatakan bahwa bahwa tindakan bebas individu yang bersifat voluntaristik yang menghasilkan realitas (struktur). ${ }^{48}$ Faktanya, usaha yang dilakukan oleh pesantren tersebut mampu mendorong (memobilisasi) kehidupan masyarakat ke arah yang lebih baik. Salah satu contohnya adalah Pesantren Maslakul Huda, Kajen, Margoyoso, Pesantren al-Isti'anah, Plangitan, Pati, dan Pesantren Mambaul Huda, Kembang, Dukuhseti yang berperan memberdayakan ekonomi masyarakat dan pengembangan ekonomi Islam. Ketiga pesantren ini dapat disebut mewakili sebagai salah satu kelembagaan ekonomi Islam (Islamic social enterprise). ${ }^{49}$ Bahkan dalam lingkup pedesaan-Jawa dan Madura - keterlibatan kiai di bidang politik didorong karena kepentingan umum dan mengintegrasikan agama dengan masyarakat dalam berbagai bidang. ${ }^{50}$

Semua aspek yang dilakukan pesantren tersebut terformulasi secara fundamental pada sumberdaya sosial yang di dalamnya tersimpul komponen kepercayaan (trust). Di mana varian ini merupakan konfiguratif sosok inovator yang dilihat oleh masyarakat ketika ia menyampaikan dan mengimplementasikan gagasan-gagasannya, sehingga dengan gagasan tersebut ia memobilisasi masyarakat menuju masyarakat yang mandiri secara ekonomi. Tidak jarang pula banyak masyarakat yang datang ke kiai menginginkan petunjuk dalam amalan ibadah; dan banyak pula di antara mereka datang berharap barakah dari kiai atau atau berharap agar kiai dapat menyembuhkan penyakit dengan cara-cara penyembuhan spiritual; atau pun berharap kiai dapat membantu mendoakan agar cita-cita atau harapan yang sedang dikejar berhasil. ${ }^{51} \mathrm{Hal}$ ini berarti, pesantren melalui kiainya

${ }^{48}$ Luckmann, Tafsir Sosial atas Kenyataan: Risalab tentang Sosiologi Pengetabuan, 30.

${ }^{49}$ Choir, "Manajemen Entrepreneurship Berbasis Pesantren dalam Pengembangan Sumber Pembiayaan Pendidikan: Studi Multikasus pada Pondok Pesantren Maslakul Huda Kajen Margoyoso, Pondok Pesantren Al-Isti'anah Plangitan Pati, dan Pondok Pesantren Manbaul Huda Kembang Du.”, 83.

${ }^{50}$ Imam Suprayogo, Kyai dan Politik: Membaca Citra Politik Kyai (Malang: UINMalang Press, 2009).

51 Zamakhsyari Dhofier, Tradisi Pesantren: Studi Pandangan Hidup Kyai dan Visinya Mengenai Masa Depan Indonesia (Jakarta: LP3ES, 2011), 208. 
memiliki kepercayaan yang tinggi dari masyarakat di berbagai bidang kehidupan masyarakat.

Wajar apabila varian ini sangat mempengaruhi polaritas mobilisasi pesantren untuk mewujudkan masyarakat yang sesuai dengan visinya. Kemampuan ini bisa dikatakan sebagai modal sosial ${ }^{52}$ yang dalam diri pesantren dimanfaatkan untuk membawa gagasannya pada dunia praksis. Oleh sebab itu, menurut Mary Holmes dikatakan bahwa seseorang yang mempunyai modal sosial yang tinggi ia akan membedakan dirinya dengan lainnya. ${ }^{53}$ Lazim apabila George Ritzer menyatakan, modal sosial terdiri dari relasi-relasi sosial yang bernilai di antara orang-orang, ${ }^{54}$ yang perlu diukur salah satunya dengan kepercayaan dan koneksi interpersonal (jaringan). ${ }^{55}$ Sedangkan bagi James S. Coleman, modal sosial merupakan seperangkat sumberdaya yang menjadi sifat dalam hubungan (koneksi interpersonal) yang berguna bagi perkembangan kognitif dan sosial. ${ }^{56}$

Dengan dua komponen tersebut (jaringan sosial dan kepercayaan), lembaga pendidikan Islam (pesantren) mampu untuk menerobos keterbelakangan masyarakat menjadi tata masyarakat yang mempunyai modal ekonomi yang mapan. Hal ini seakan mengukuhkan tesis Pierre Bourdieu, bahwa seseorang yang banyak memiliki modal sosial merupakan sosok yang pertama menuju posisi yang baru. ${ }^{57}$ Dengan dua hal itu pula, lembaga pendisikan Islam seperti pesantren merancang bersama-sama mengimplementasikangagasan pembaharuan. Untukitu, strategiperubahan

${ }^{52}$ Francis Fukuyama, Trust: Kebajikan Sosial dan Penciptaan Kemakmuran (Yogyakarta: Qalam, 2002).

53 Mary Holmes, "Social Theory of the Body," in The Routledge Companion to Social Theory, ed. Anthony Elliott (London: Routledge, 2010), 111.

54 Ritzer, Sociological Theory, 533.

55 Marc Hooghe \& Dietlind Stolle, "Introduction: Generating Social Capital," in Generating Social Capital: Civil Society and Institutions in Comparative Perspective, ed. Marc Hooghe \& Dietlind Stolle (New York: Palgrave Macmillan, 2003), 2.

56 Coleman, Dasar-Dasar Teori Sosial: Foundations of Social Theory, 415.

${ }^{57}$ Cheryl Hardy, "Hysteresis," in Pierre Bourdieu: Key Concepts, ed. Michael Grenfell (Stocksfield: Acumen Publishing Limitid, 2008), 135. 
yang melibatkan penduduk lain (individu) sebagai agen perubahan, harus memilih individu yang benar-benar memiliki pengaruh di dalam kelompok tersebut $^{58}$ terlebih dalam struktur masyarakat. Begitu pula sebaliknya, kelompok dapat dijadikan target maupun sebagai perantara perubahan. Bila kelompok atau struktur sosial yang menjadi target, diasumsikan perubahan suasana akan mempengaruhi individu. Nilai, sikap, dan perilaku individu akan diubah melalui struktur sosial atau melalui perubahan kelompok yang menjadi tempat individu berpikir dan bertindak $;^{59}$ hal ini yang oleh Peter L. Berger dan Thomas Luckmann dikatakan sebagai kemampuan objektivasi yaitu kemampuan memanifestasikan diri dalam produk-produk kegiatan manusia yang tersedia, baik bagi produsen-produsennya maupun bagi orang lain sebagai unsur-unsur dari dunia bersama. ${ }^{60}$

Fenomena ini bisa dikatakan merupakan bentuk gerak perubahan sosial yang dilakukan pesantren dengan mendorong masyarakat pada integralisasi dalam semangat kekeluargaan (brotherhood) yang ditopang asas kepercayaan, sehingga tataran empiris menjadi dasar kuat pada hubungan profesional. ${ }^{61}$ Artinya, perubahan sosial tersebut memiliki pengaruh yang sangat luas dan berhubungan langsung dengan perubahan-perubahan lainnya seperti perubahan ekonomi dan politik. ${ }^{62}$ Perubahan ini dimotori oleh suatu kekuatan yang muncul dari rahim serangkaian nilai dan norma informal yang dimilki bersama di antara para anggota suatu kelompok masyarakat yang memungkinkan terjadinya kerjasama di antara mereka-

58 Martono, Sosiologi Perubahan Sosial: Perspektif Klasik, Modern, Posmodern, dan Poskolonial, 255.

59 Robert H. Lauer, Perspektif tentang Perubahan Sosial (Jakarta: Renika Cipta, 2003), 481.

${ }^{60}$ Luckmann, Tafsir Sosial atas Kenyataan: Risalab Tentang Sosiologi Pengetabuan, 47.

${ }^{61}$ Gillian Ruch, "The Contemporary Context of Relationship-Based Practice," in Relationship-Based Practice Social Work: Getting to the Heart of Practice, ed. et all Gillian Ruch (London: Jessica Kingley Publishers, 2010), 23.

${ }^{62}$ Nicos Mouzelis, Sociological Theory: What Went Wrong? (Diagnosis and Remedies) (London: Routledge, 2005), 42. 
lazim dikatakan sebagai modal sosial. ${ }^{63}$ Dengan modal sosial pesantren mempunyai kemampuan bekerja sama untuk mencapai tujuan bersama di dalam berbagai bidang, sehingga pada saat tertentu modal sosial dapat memfasilitasi derajat inovasi dan daya adaptasi pesantren dan masyarakat sekitar pesantren. Wajar jika ada kalangan yang menilai bahwa modal sosial merupakan aset yang mampu untuk membangkitkan masa depan; ${ }^{64}$ dan dengannya pula tata kelembagaan pesantren dalam melakukan perubahan sosial kemasyarakatan dapat terbangun secara konstruktif.

\section{Penutup}

Berdasar pada uraian di atas, bisa dikatakan bahwa modal sosial dapat digunakan untuk segala kepentingan pesantren dengan dukungan sumberdaya fisik dan pengetahuan budaya yang dimiliki. Melalui jaringan sosial (networking) dan kepercayaan (trust), ternyata pesantren mampu menerobos keterbelakangan masyarakat menjadi tata masyarakat yang mempunyai modal ekonomi yang mapan. Menariknya, gerak perubahan sosial yang dilakukan pesantren dengan mendorong masyarakat pada integralisasi keagamaan di berbagai bidang dalam semangat kekeluargaan (brotherhood) yang ditopang asas kepercayaan, sehingga tataran empiris menjadi dasar kuat pada hubungan profesional.

Dengan demikian, modal sosial di pesantren merupakan sumberdaya yang dipandang sebagai investasi untuk mendapatkan sumberdaya baru untuk melakukan perubahan sosial kemasyarakatan. Apalagi pesantren telah memiliki kepercayaan dari masyarakat untuk membentuk jiwa profetik santri_-dan masyarakat—yang mampu menerjemahkan teks-teks normatif keagamaan dalam kehidupan keseharian civitas pesantren dan

${ }^{63}$ Fukuyama, Trust: Kebajikean Sosial dan Penciptaan Kemakmuran, xii.

${ }^{64}$ Elinor Ostrom \& T.K. Ahn, "The Meaning of Social Capital and Its Link to Collective Action," in Handbook of Social Capital: The Troika of Sociology, Political Science and Economics, ed. Gert Tinggaard Svendsen \& Gunnar Lind Haase Svendsen (Massachusetts: Edward Elgar Publishing, Inc., 2009), 19. 
melahirkan sikap toleran, moderat, selektif bahkan semangat transformatif di ranah sosial.

\section{Referensi}

Ahn, Elinor Ostrom \& T.K. "The Meaning of Social Capital and Its Link to Collective Action." In Handbook of Social Capital: The Troike of Sociology, Political Science and Economics, edited by Gert Tinggaard Svendsen \& Gunnar Lind Haase Svendsen, 19. Massachusetts: Edward Elgar Publishing, Inc., 2009.

Albrow, Martin. Sociology: The Basics. London: Routledge, 2003.

Benne, Kenneth D. "The Current State of Planned Changing in Persons, Groups, Communities, and Societies." In The Planning of Change, edited by at all Warren G. Bennis, 79. New York: Holt, Rinehart and Winston, 2008.

Bruinessen, Martin Van. NU: Tradisi, Relasi-Relasi Kuasa, Pencarian Wacana Baru. Yogyakarta: LKiS, 1999.

Choir, Abu. "Manajemen Entrepreneurship Berbasis Pesantren dalam Pengembangan Sumber Pembiayaan Pendidikan: Studi Multikasus pada Pondok Pesantren Maslakul Huda Kajen Margoyoso, Pondok Pesantren Al-Isti'anah Plangitan Pati, dan Pondok Pesantren Manbaul Huda Kembang Du." UIN Maulana Malik Ibrahim, Malang, 2016.

Chossudovsky, Michel. The Globalization of Poverty and The New World Order. Canada: Global Research, Center for Research on Globalization, 2003.

Coleman, James S. Dasar-Dasar Teori Sosial: Foundations of Social Theory. Bandung: Nusa Media, 2011.

Damopolii, Muljono. "Pembaruan Pendidikan Islam di Makassar:

Studi Kasus Pesantren Modern Pendidikan Al-Qur'an IMMIM Tamalanrea Makassar.” UIN Syarif Hidayatullah Jakarta, 2006.

Dhofier, Zamakhsyari. Tradisi Pesantren: Studi Pandangan Hidup Kyai dan Visinya Mengenai Masa Depan Indonesia. Jakarta: LP3ES, 2011.

Djamil, Abdul. Perlawanan Kiai Desa: Pemikiran dan Gerakan Islam KH. Ahmad Rifa'i Kalisalak. Yogyakarta: LKiS, 2001. 
Dunia, Staf Bank. Era Baru dalam Pengentasan Kemiskinan di Indonesia: Iktisar. Jakarta: The World Bank Office, 2006.

Efendi, Nur. Manajemen Perubahan di Pondok Pesantren: Konstruksi Teoritik dan Praktik Pengelolaan Perubahan Sebagai Upaya Pewarisan Tradisi dan Menatap Tantangan Masa Depan. Yogyakarta: Teras, 2014.

Etzioni, Eva Etzioni-Halevy \& Amitai. Social Change: Sources, Patterns, and Sequences. New York: Basic Books, 1974.

Field, John. Social Capital. London: Routledge, 2008.

Fukuyama, Francis. Trust: Kebajikan Sosial dan Penciptaan Kemakmuran. Yogyakarta: Qalam, 2002.

Giddens, Anthony. Melampaui Ekstrim Kiri dan Kanan: Masa Depan Politik Radikal. Yogyakarta: Pustaka Pelajar, 2009.

Goodman, George Ritzer \& Douglas J. Teori Sosiologi Modern. Jakarta: Prenada, 2011.

Hardy, Cheryl. "Hysteresis." In Pierre Bourdieu: Key Concepts, edited by Michael Grenfell, 135. Stocksfield: Acumen Publishing Limitid, 2008.

Hauberer, Julia. Social Capital Theory: Towards a Methodological Foundation. Germany: Spinger Fachmedien, 2011.

Holmes, Mary. "Social Theory of the Body." In The Routledge Companion to Social Theory, edited by Anthony Elliott, 111. London: Routledge, 2010.

Horikoshi, Hiroko. Kyai dan Perubahan Sosial. Jakarta: P3M, 1987.

Kafid, Nur. "From Personal to Social Transformation: A Phenomenological Study on the Life of "Kyai Kampung." Komunitas: International Journal of Indonesian Society and Culture 6, no. 3 (2014): 336-344.

Khitam, Husnul. "Kontekstualisasi Teologi sebagai Basis Gerakan Ekologi." DINIKA: Academic Journal of Islamic Studies 1, no. 2 (2016): 143-164.

Kitab, Tim Penulis Rumah. Pendidikan Karakter Berbasis Tradisi Pesantren. Jakarta: Rumah Kitab Kerjasama Renebook, 2014.

Latifah, Emmy. "Harmonisasi Kebijakan Pengentasan Kemiskinan di Indonesia yang Berorientasi pada Millenium Development Goals." Dinamika Hukum 11, no. 3 (2011): 402. 
Lauer, Robert H. Perspektif Tentang perubahan Sosial. Jakarta: Renika Cipta, 2003.

Lemert, Anthony Elliott \& Charles. The New Individualism: The Emotional Costs of Globalization. London: Routledge, 2006.

Li, Tania Murray. The Will to Improve: Perencanaan, Kekuasaan, dan Pembangunan di Indonesia. Jakarta: Marjin Kiri, 2012.

Lin, Nan. A Network Theory of Social Capital. Edited by et all Dario Castiglione. Oxford: Oxford University Press, 2008.

Luckmann, Peter L. Berger \& Thomas. Tafsir Sosial atas Kenyataan: Risalah tentang Sosiologi Pengetahuan. Jakarta: LP3ES, 1990.

Magee, Bryan. Memoar Seorang Filosof: Pengembaraan di Belantara Filsafat. Bandung: Mizan, 2005.

Martono, Nanang. Sosiologi Perubahan Sosial: Perspektif Klasik, Modern, Posmodern, dan Poskolonial. Jakarta: Rajawali Pers, 2011.

Mouzelis, Nicos. Sociological Theory: What Went Wrong? (Diagnosis and Remedies). London: Routledge, 2005.

Newton, Kenneth. Social Capital and European Democracy. Edited by Jan Van Dept. London: Routledge, 1999.

Penulis, Tim. Rethinking Poverty: Report on the World Social Situation 2010. New York: United Nation, 2009.

Putnam, Robert D. Bowling Alone: The Collapse and Revival of American Community. New York: Simon \& Schuster, 2000.

. Making Democracy Work: Civic Traditions in Modern Italy. Princeton: Princeton University Press, 1993.

Ritzer, Gergoge. Sociological Theory. New York: McGraw-Hill, 2011.

Rosyad, Soleh. Drs. K.H. Abmad Rifa'i Arief: Kiprah Kyai Entrepreneur. Jakarta: Grasindo, 2011.

Ruch, Gillian. "The Contemporary Context of Relationship-Based Practice." In Relationship-Based Practice Social Work: Getting to the Heart of Practice, edited by et all Gillian Ruch, 23. London: Jessica Kingley Publishers, 2010.

Schaefer, Richard T. Sociology: A Brief Introduction. New York: Mc-GrawHill, 2010.

Scott, John. Sosiologi: The Key Concept. Jakarta: Rajawali Pers, 2011. 
Seligman, Adam. The Problem of Trust. Princeton: Princeton University Press, 1997.

Smart, George Ritzer \& Barry, ed. Handbook of Social Theory. London: Sage Publications, 2003.

Soekanto, Soerjono. Sosiologi: Suatu Pengantar. Jakarta: Rajawali Pers, 2007.

Soetomo. Masalah Sosial dan Upaya Pemecahannya. Yogyakarta: Pustaka Pelajar, 2008.

Statistik, Subdirektorat Indikator, ed. Statistik Indonesia 2014. Jakarta: Badan Pusat Statistik, 2014.

Stolle, Marc Hooghe \& Dietlind, ed. Generating Social Capital: Civil Society and Institutions in Comparative Perspective. New York: Palgrave Macmillan, 2003.

- "Introduction: Generating Social Capital." In Generating Social Capital: Civil Society and Institutions in Comparative Perspective, edited by Marc Hooghe \& Dietlind Stolle, 2. New York: Palgrave Macmillan, 2003.

Stolley, Kathy S. The Basics of Sociology. London: Greenwood Press, 2005.

Sulaiman, In'am. Masa Depan Pesantren: Eksistensi Pesantren di Tengah Gelombang Modernisasi. Malang: Madani, 2010.

Suprayogo, Imam. Kyai dan Politik: Membaca Citra Politik Kyai. Malang: UIN-Malang Press, 2009.

Suwarno. "Pergeseran Pemikiran Masyarakat dalam Memilih Lembaga Pendidikan Islam di Kabupaten Ngawi Jawa Timur." Salam 18, no. 1 (2015): 151.

Syarifuddin, Hamdan Farchan \&. Titik Tengkar Pesantren: Resolusi Konflik Masyarakat Pesantren. Yogyakarta: Pilar Religia, 2005.

Turner, Simon Susen \& Bryan S., ed. The Legacy of Pierre Bourdieu: Critical Essays. London: Anthem Press, 2011.

Umiarso, Ninik Masruroh \&. Modernisasi Pendidikan Islam Ala Asyumardi Azra. Yogyakarta: Ar-Ruzz Media, 2011.

Vickers, Adrian. A History of Modern Indonesia. Cambridge: Cambridge University Press, 2013.

Yasmadi. Modernisasi Pesantren: Kritik Nurcholish Madjid terbadap Pendidikan Islam Tradisional. Jakarta: Ciputat Press, 2002. 